\title{
A clínica fenomenológico-existencial: um saber-fazer pós identitário
}

\section{The phenomenological-existential clinic: a post-identitarian know-how}

DOI: $10.54022 / \operatorname{shsv3n1-017}$

Recebimento dos originais: 05/12/2021

Aceitação para publicação: 05/01/2022

\section{Felipe Miranda Zanetti \\ Especialista em psicologia clínica fenomenológico-existencial (UNIFEG, 2020) \\ Docente do Instituto Municipal de Ensino Superior de Catanduva - IMES \\ Psicólogo e supervisor clínico. \\ E-mail: felipezanetti.mz@gmail.com}

\section{RESUMO}

A psicologia, como área de conhecimento das ciências humanas, cumpre em sua clínica a função de cuidado à vida a partir de suas intervenções, que por sua vez estão quase sempre pautadas no positivismo. Este trabalho visa pensar, contrário às práticas naturalistas e indutivas, caminhos para a construção de uma clínica fenomenológico-existencial que seja transgressora das normas padronizadas como adequadas no percurso da história e em sua influência na construção dos modos de ser. Entende-se que a clínica aqui defendida precisa se opor ao identitarismo metafísico, ela pode ser articulada a partir de um saber-fazer fenomenológico, um conhecimento que não se separa de sua prática ativa na relação de cuidado com o outro; é uma prática que nos afasta das ortopedias das existências, tornando-se portanto uma psicologia pós-identitária. Essa clínica é um fazer que se exercita pela paciência.

Palavras-chave: Psicologia Fenomenológica, Fenomenologia Existencial, Existencialismo, Liberdade, Clínica Psicológica.

\section{ABSTRACT}

Psychology, as an area of knowledge of the human sciences, fulfills in its clinical practice the function of caring for life through its interventions, which are almost always based on positivism. This work aims to think, contrary to naturalistic and inductive practices, of ways to build a phenomenological-existential clinic that transgresses the standardized norms as adequate throughout history and their influence on the construction of ways of being. It is understood that the clinic defended here needs to oppose metaphysical identitarianism, it can be articulated from a phenomenological know-how, a knowledge that cannot be separated from its active practice in the care relationship with the other; it is a practice that moves us away from the orthopedics of existences, becoming therefore a post-identitarian psychology. This clinic is a doing that is exercised by patience. 
Keywords: Phenomenological Psychology, Existential Phenomenology, Existentialism, Freedom, Psychological Clinic.

\section{INTRODUÇÃO}

A psicologia enquanto área do conhecimento das ciências humanas possui uma vasta gama de bases para a clínica psicológica, essas bases, teorias que dão fundamento para a atuação profissional dos que ocupam o lugar clínico terapêutico, direcionam propostas sempre distintas para que se dê fundamento ao que se faz com o paciente.

A fenomenologia, no intuito de conhecer as coisas da maneira como se mostram, ou seja, conhecer "as coisas em si mesmas" (Feijoo, 2004) ganhou, dentro da clínica psicológica, também, um lugar de atuação; assim sendo, esse trabalho vai buscar, a partir de autores da psicologia e da filosofia, traçar breves compreensões de como pode se dar, dentro deste recorte, a clínica fenomenológico-existencial em suas mais diversas formas de acontecer.

A partir da morte de Deus e da afirmação da performance histórica da vida humana pensaremos como a psicologia pós-identitária, um conceito de Alexandre Cabral (2018), se articula com o saber-fazer, cunhado por Ana Maria Feijoo (2017), dentro da atuação do clínico fenomenólogo. Sendo um espaço não identitário, quer-se propor caminhos para a clínica a partir de seus limites levando em conta seu caráter provocativo e aberto, ou seja, indefinido, buscando o poderser mais próprio de cada existência sem que para isso esta clínica que aqui se articula faça uso de determinações identitárias ou de manutenções das formasde-ser hegemônicas e estabelecidas pelos padrões de moralidade vigentes nas relações interpessoais. Pensaremos, portanto, a corrosão dos valores cristalizados e que geram violência às particularidades humanas dissonantes do que se entende através de preconceitos sedimentados historicamente. Fazer fenomenologia , portanto, não resume-se em adequar.

\section{A CLÍNICA E SUAS FRONTEIRAS}

Eu antes tinha querido ser os outros para conhecer o que não era eu. Entendi então que eu já tinha sido os outros e isso era fácil. Minha experiência maior seria ser o outro dos outros: e o outro dos outros era eu. 
Parece ser essa a maior tarefa, o maior querer da clínica existencialista: abrir caminhos para que o outro seja apenas ele mesmo dentro das milhares formas possíveis dos sentidos do mundo histórico ${ }^{1}$, o outro dos outros; que seja ele fruto de seu modo próprio de organizar as fronteiras de sua vida e assim delimitar, da maneira mais liberta possível, seu espaço de vivência, ou seja, os horizontes que possam ser estabelecidos, e ultrapassados se assim o movimento performático do existir puder levar a fazer. Essa libertação precisa necessariamente passar pelo processo de reconhecimento, de clarificação, em relação aos "comos" próprios da história constitutiva da vida de cada sujeito - não se liberta sem conhecer quais amarras tornam a clausura possível.

Essa clínica aqui tratada possui um modo de acontecer, e todo modo de identificação se dá pelo estabelecimento de fronteiras, limites, como a margem que delimita a forma de um rio. (Pompéia; Sapienza, 2011)

Sem dúvida, o limite mais destacado que se dá para os fenomenólogos é o da moral, fronteira que delimita o clínico(a) ao movimento apenas nos espaços onde a moral não seja determinadora de seu fazer, de suas intervenções, de seu pensar-com-o-outro. Claro, isso já foi esclarecido por Husserl quando este defende a suspensão e o abandono da atitude natural (Feijoo, 2012; Holanda, 2014). Fazer fenomenologia é assumir uma postura que imprima no movimento profissional um modo aberto de deixar-ser, o agir fenomenológico precisa ir tomando forma de maneira que o raciocínio clínico ganhe teores de suspensão e, realmente, admita o outro como um campo de possibilidades aberto e indeterminado que independe do desejo do profissional sobre os encaminhamentos para o modo de existir do paciente. Tomemos isso como deixar-ser.

Quer-se pensar esse fazer clínico como uma atitude oposta a da capacidade de exercer força modeladora, no sentido de fazer acontecer a partir

\footnotetext{
${ }^{1}$ Esclareço que tal afirmação não deve, de modo algum, considerar que possa ser possível que qualquer pessoa se constitua de forma apartada dos processos e relações históricas, todo modo de ser somente se dá pela base histórica que o mundo oferece em sua facticidade. Essa afirmação trata muito mais de uma não obrigação a estar rendido às determinações tornando o movimento criativo do existir algo estéril. É possível transitar pelas determinações.
} 
de um poder terapêutico que seja mais forte que a liberdade ontológica de todo sujeito. Não é que a clínica fenomenológico-existencial não tenha força no que se propõe a fazer, mas se nega a exercer força no sentido conformativo, forçando os modos-de-ser aos padrões identitários historicamente articulados como adequados. Mas fica a questão: se há uma força , e se essa força não determina, como ela se dá nessa relação?

\section{A MORTE DE DEUS E A ANÁLISE EXISTENCIAL}

Alexandre Cabral (2018), quando escreve sobre a "psicologia pósidentitária" nos recorda, já em sua introdução, que Nietzsche, anunciando a morte de Deus, também anuncia o caráter histórico, e portanto, o caráter existencial de devir que o humano tem como essência em seu ser.

O que Cabral mostra é que desde Nietzsche há a percepção de que existir enquanto sujeito está sempre vinculado ao histórico como espaço para a articulações de ser. Quando se desconstrói a noção da onipotência divina, ou seja, o poder das determinações metafísicas em detrimento dos modos de existências, assume-se por conseguinte o caráter histórico de cada performance existencial, assim, só se pode conhecer uma existência a partir da compreensão de seu desenrolar histórico e das relações constituídas a partir deste, não se pode perceber nenhum movimento humano sem que se volte um olhar atento para os detalhes, os encontros e desencontros, os sentidos, as articulações estabelecidas no tempo da existência.

O terapeuta desavisado da morte de Deus, e que tenta buscar delineamentos pré-estabelecidos, parece um pretendente a assumir o lugar identitário, está totalmente tomado pela sombra dessa noção "desistoricisante".

É pretensioso querer que a terapia exerça técnicas de conserto da vida sendo a vida um campo de constituição acontecendo a partir do indeterminado (Casanova, 2017), permeado por atravessamentos diversos, plurais, não mensuráveis pelo positivismo sedento de enquadramentos.

Quando psicólogos e psicólogas - embasados na fenomenologia esquecem desse caráter de devir da existência, sem dúvida estão tomados pela sombra de Deus que ainda nos cerca advinda das matrizes moralistas da psicologia e também das ciências tradicionais. Dizendo de maneira ainda mais 
clara, o fazer da psicologia fenomenológico-existencial precisa estar consolidado no entendimento do humano a partir de uma ontologia que não segue padrões naturalizantes dos modos de ser (Zanetti, 2020), cada encontro com cada paciente precisa estar disposto a propor um modo de relação aberto e disponível para compreender cada contexto e cada experiência da maneira como essa chama a ser entendida.

Quando a moral, as definições de adequação, tomam os espaço de trabalho psicológicos, está sendo ultrapassando o horizonte que delimita a ação clínica direcionada pelo método fenomenológico.

Assim, é importante perguntar: o que do fazer psicológico ainda é tomado pela sombra de Deus da qual Nietzsche já nos advertiu existir? Então, o que pode um paciente dentro dessa nossa perspectiva? O que faz um terapeuta quando vê seu paciente, após meses debatendo um tema aparentemente já "resolvido" escolher pelo extremo contrário? Será feita uma exemplificação a seguir para melhor compreender-se o que se quer dizer: ${ }^{2}$

\section{A EXPERIÊNCIA DE CLARICE}

Clarice um dia me disse: "este meu novo trabalho me gera medo, está sendo muito difícil e a carga horária é bastante extensa. Meu banco de horas já está estourado com apenas dois meses de trabalho; porém, preciso deste trabalho para poder ter meu financiamento aprovado e comprar meu apartamento. Não consigo mais morar com minha família, está muito difícil lá."

Ouvindo Clarice compreendo seu contexto de vida, já temos um vínculo já há um tempo. O terapeuta diz a ela: percebo que você também não está muito motivada a permanecer neste lugar, aliás, desde o começo você me relatou tratar esse emprego como um degrau, iria usá-lo para crescer.

Ela segue: "Sim, e continua sendo esse o projeto. Porém, deixar esse trabalho me deixa insegura, não sei se a clínica - Clarice trabalha na área da saúde e atende também em sua clínica particular - me daria a renda necessária para bancar minhas contas. Eu quero muito já deixar esse emprego, mas tenho medo."

\footnotetext{
${ }^{2}$ Esse caso não diz respeito a uma experiência clínica real, o nome citado é fictício é a história também é criada com base em experiências clínicas mas sem que seja atribuída a algum paciente em específico.
} 
O terapeuta então lhe diz: quer dizer que você vai continuar em um trabalho que não gosta e que tem receio que lhe faça mal por conta da carga horária e da exigência por medo?

Ela prontamente responde: "sim".

O que deveria um terapeuta fenomenólogo dizer a partir disso? Prontamente vem à ideia um discurso - coerente com o mundo moderno - de que seria a psicologia uma área da ciência que trabalha para que as pessoas ultrapassem seus medos e inseguranças. Então, nesse sentido, deveria o terapeuta trabalhar para que Clarice deixasse seu medo e tivesse coragem de seguir seus desejos?

É sedutor que se faça isso, é bastante convidativo assumir o lugar de detentor maior do saber sobre os modos de viver, ora, o trabalho a impede de atuar mais em coisas que sejam do seu desejo e de seu agrado, ela não sente prazer em estar nesse espaço, seria "justo" - segundo uma postura identitária que a terapia a auxiliasse a abandonar o que lhe causa desconforto e impossibilita seu bem-estar.

Se assim agir a psicologia, sem dúvida estará tomada pela sombra de Deus que antes Nietzsche já anunciou ter morrido, ou seja, estará tomada das determinações metafísicas que direcionam o adequado à vida. Atuar em direção a destituir o outro da liberdade em posicionar sua existência seria imprimir aí uma noção moralizada de que medos são vivências somente prejudiciais à existência, e que deixar de agir por medo seria algo inadequado para um sujeito que busca autenticidade.

Pois não é autêntico escolher e agir tendo clareza de seus medos?

Não cabe à clínica que delineia seu olhar pela fenomenologia existencialista suprimir a possibilidade de que o outro faça com sua dor aquilo que melhor lhe parecer, não se deve retirar do outro a possibilidade de que este escolha sofrer pelo tempo que lhe cabe independente de quanto tempo isso dure; precisa ser a terapia um espaço de clareira que possibilite ao que busca auxílio psicológico compreender como suas dores se articulam em suas relações com o mundo, mas não cabe à clínica direcionar ações para o outro a partir dessas compreensões obtidas no processo terapêutico.

Cada sujeito humano constitui - ou deveria constituir - vida a partir de seu 
modo próprio de articular sentidos, que se abrem a partir de seu campo de articulação histórica com seu horizonte. ${ }^{3}$

É justo que possa essa paciente aqui exemplificada experimentar as aberturas de possibilidades que se apresentarão a partir de sua escolha, independente de qual seja. Não cabe ao terapeuta, ao menos ao fenomenólogo, retirar do outro a experiência que se desvela a partir das direções que este mesmo vislumbra como possíveis para si, não há como dizer que esse não seria o caminho que possibilitaria à paciente em questão encontrar arranjos mais próprios para sua decadência na facticidade do mundo.

Quando, dentro da fenomenologia, embasados no pensamento heideggeriano, pensamos a questão da liberdade, estamos diretamente afirmando que não existem maneiras estabelecidas previamente para que se encaminhe uma vida para alguma direção; liberdade pressupõe, já, que surgimos no mundo com nossa nadidade estrutural, e a partir disso decaímos em um mundo já dado (Casanova, 2017), o que não significa que arranjos específicos de existência sejam mais corretos que outros.

Ser fenomenólogo, dentro de propostas terapêuticas, coloca o profissional no lugar de acompanhar o outro pelos caminhos que este decide seguir, mas não direcionar caminhos adequados, pois não há adequação homogênea sem que para isso se dê uma concepção de modos de existir pautados em alguma natureza substancial.

A psicologia não pode tudo, e não se deve descuidar do esforço de não se render à adequação do outro aos padrões. Ser fenomenólogo é admitir a impotência, é negar a potência da técnica que nos empodera como resolutores de vidas problemáticas. Parece simples, mas como nos recorda Sá (2017) a técnica é sedutora, e constantemente nos chama às práticas resolutivas e corretivas.

Foucault (2019) demonstrou como o mundo ocidental se determina a partir de uma vontade de saber, ou seja, como suas práticas científicas e suas relações mais diversas se conformam com base em um horizonte de

\footnotetext{
${ }^{3}$ Penso que caberia discutirmos também de que maneira as relações de poder determinam abertura de sentidos específicos para pessoas específicas. Classe social, cor da pele, orientação sexual entre tantas outras características são determinantes para delimitar quais caminhos são possíveis para quais sujeitos, e embora seria de extrema importância descrever isso aqui, o espaço não seria suficiente para a explanação. Para mais detalhes consultar Alexandre Cabral (2020).
} 
compreensão que prega um saber infinito, um conhecer incontrolável em relação a qualquer fenômeno que se dê no mundo. Além disso, recorda que esse tipo de busca pelo saber não serve apenas a um conhecimento despretensioso, mas sim a um modo de busca pelo saber que tende ao conhecer para controlar (Foucault, 2013).

É nesse horizonte ociedental que as práticas científicas - inclusive as psicológicas - se dão. É em meio a esses sentidos que o fazer clínico acontece. Assim, é preciso constantemente um esforço na direção de não ter um fazer rígido diante desse mundo técnico.

Não devemos ser prescritivos, mas sim descritivos diante das análises de cada articulação histórica das existências dispostas a análise , e tal descrição não visa o controle ou a correção, mas simplesmente a tematização dos dramas de ser o que se vem sendo.

É possível já reconhecer, portanto, que a psicologia fenomenológicoexistencial trabalha direcionada à liberdade do ser. É isso o que nos esclarece Ana Maria Feijoo, e sobre isso a seguir falaremos.

\section{SABER-FAZER UMA CLÍNICA PARA A LIBERDADE}

Para Feijoo (2017), a clínica fenomenológica se estrutura por um saberfazer, indivisível, que não se separa em momento algum na prática do terapeuta.

Esse termo, de maneira clara, pontua que prática e conhecimento são, cooriginários para os clínicos, e também deixa claro que todo saber exerce força no modo como a clínica se articula e cria espaços de cuidado dentro dos settings terapêuticos ${ }^{4}$.

Se saber e fazer são indivisíveis, a forma como se conhece as bases desse trabalho diz respeito à maneira como se irá incorporar a postura diante da existência do outro; é preciso saber do que se trata fenomenologia existencial para poder incorporar esse conhecimento diante das propostas de cuidado ao outro.

Saber-fazer diz respeito a estar totalmente contaminado pelo modo fenomenológico de conhecer o que se mostra, tornar comum a postura da crítica e da suspensão, habituar-se a libertar ao invés de enclausurar.

\footnotetext{
${ }^{4}$ É importante salientar e relembrar: não se deve pensar este setting como uma sala de atendimento, mas como qualquer espaço onde uma relação de cuidado existencial se dê.
} 
É preciso saber-fazer para com tranquilidade poder-ouvir, sem forçar o que é ouvido a encaixar-se em padrões mais confortáveis para quem ouve, ou também a formas mais adequadas às ideias indutivas das ciências tradicionais. Saber-fazer parece dizer respeito a um modo de escuta e de relação, que por ter bases fenomenológicas, acontece deixando-ser, dando espaço para que o outro possa acontecer da maneira como é, independente da estranheza que isso possa suscitar.

Em fenomenologia não se pretende recuperar existências fracassadas, não deve ser esse o esforço; quando é dito de uma tranquilidade quer-se referir a clareza daquilo que cabe ao clínico dentro de seu fazer, de não ser sequestrado pelas solicitações das noções do mundo moderno, que significa um esforço constante para que as noções naturalistas do mundo, a atitude natural, seja sempre suspensa em cada intervenção clínica. Suspender no fazer clínico é um esforço que se faz a partir de um saber.

Saber-fazer diz respeito a um movimento que se quer espontâneo no clínico, que a cada vez, por sua afinidade com essa maneira de olhar, já vê o mundo, dentro da clínica, pelo modo fenomenológico, tornando a clínica um espaço amplo para receber e ver o outro a partir de seu poder-ser.

A clínica se dá no momento da relação (Feijoo, 2021), no descobrir de cada relação. O interpretar precisa ser livre, e por isso tranquilo para ouvir; o esforço deve ser em cuidar para que pretensões técnicas não contaminem o "entre" da relação que na análise terapêutica se dá. É preciso afinar-se com o incerto.

Para poder saber e em consequência conseguir fazer - constituindo a unidade saber-fazer - é preciso criar afinidade com o indeterminado para que assim todo fazer se dê com base nesse pressuposto ontológico.

\section{UM SABER-FAZER PÓS-IDENTITÁRIO}

Tomando também como base a psicologia pós-identitária de Alexandre Cabral (2018), essa postura de saber-fazer já precisa, inclusive, estar atrelada a uma atitude de não manutenção das modulações estabelecidas pela moralidade histórica que permeia o atual horizonte de existência; é preciso que a conduta clínica esteja na direção contrária à tecnocracia e possa trabalhar sempre em 
direção à libertação dos enquadramentos já postos pelo mundo como uma violência identitária.

Não fazendo uma violação da liberdade de constituição dos modos-deser, trabalha-se em uma clínica da implementação das possibilidades de ser, é fundamental ter como princípio básico renegar o que Alexandre Cabral (2018) denomina de "ortopedia das existências", termo utilizado pelo autor para criticar as atitudes de correção dos modos de ser transgressores da normativa moral e dos padrões dos manuais científicos, correção aos que almejam e agem para alcançar possibilidades até então destoantes com seu horizonte de existência.

Pensa-se portanto em um saber-fazer que seja articulado a noção de nãoviolência às existências, de uma prática que não prescreva posturas a fim de melhorar o outro diante de suas experiências. É fundamental prezar por uma clínica que saiba-fazer, que saiba-ouvir e que saiba deixar-ser o que se é diante das vastas possibilidades de ser. Mas é fundamental também pensar uma prática que sustente a possibilidade de descobrir o poder-ser diante dos engessamentos identitários, uma prática terapêutica que seja memória constante do devir.

A clínica psicológica fenomenológico-existencial é transgressora, somos ou deveríamos ser - pacientemente corrosivos, serenamente (Sá, 2017) desconstrutores das estruturas da moralidade que determina que existem maneiras corretas de ser, maneiras respeitosas à natureza humana. É essa noção naturalizada que produz violências às identidades mais diversas.

Entretanto, é preciso para isso pensar um modo de fazer clínica já que está sendo proposto uma maneira de atuar diferente das já tidas como corretas, ou seja, daquelas tomadas pelo positivismo.

Não se quer aqui estabelecer técnicas específicas, ferramentas esquadrinhadas para a ação clínica, mas um dos caminhos possíveis para delinear de maneira bastante aberta uma atuação a partir da relação como bem destaca Feijoo (2021).

\section{A CLÍNICA DA PACIÊNCIA: UM LUGAR DE ESPERA.}

A clínica psicológica não deve ser um espaço de pressa, o mundo contemporâneo já o é, devemos portanto criar um lugar propício à calma, à nãopressa, para que o outro no seu tempo possa se desvelar. 
Entende-se que a serenidade em Heidegger (Sá, 2017) diz respeito a isso, à tranquilidade que deve se estruturar quando pessoas estão reunidas para tratar das dores e das articulações que conferem sentido aos modos-de-ser.

Pode-se pensar assim: perder algo que tem grande importância e que se faz constitutivo para a existência e seus desdobramentos, machuca; arrancar do outro aquilo que the faz ser si mesmo, o que confere sentido às suas ações, gera prejuízo. João Augusto Pompeia (2000) nos ensina isso:

Frequentemente encontramos certa inquietação do terapeuta por fazer seu cliente "cair na real". Importante é lembrar aqui que "na real" só se cai. Ninguém "sobe para a real". Esse movimento de descida, especialmente se há pressa para descer, significa tombo. Quando nos precipitamos "na real" porque estamos com pressa, sem preparo para a queda, estamos nos "esfolando na real" (p.37).

Ter pressa para ver o que solicita ser visto não parece, para a fenomenologia existencialista dentro da clínica, um caminho coerente com esse método que requer paciência para o desvelamento.

Fernando Pessoa (2019, p.22) também contribui para essa compreensão. Em suas palavras: "tudo isso se tornou parte da minha vida; não poderia deixar tudo isso sem chorar, sem compreender que, por mal que me parecesse, era parte de mim que ficava com eles todos, que o separar-me deles era uma metade e semelhança da morte".

Mudanças, perdas, desarranjos, isso gera dor. É importante ser tranquilo para que não acabe por ferir ainda mais o já ferido pelas restrições do mundo contemporâneo dotado de fórmulas inúmeras para o viver.

É preciso perceber que o sujeito submerso nos preconceitos do mundo é um sujeito com um campo de compreensão específico, e a modificação desse campo pressupõe a queda tratada acima, pressupõe a quebra de convicções já estabelecidas. São essas compreensões que solidificam e modulam os modosde-ser de uma existência qualquer, portanto, modificá-las significa arrancar do outro 0 que lhe concede estabilidade para ser. Desestabilizar de maneira apressada e desavisada pode, talvez, prejudicar mais.

Como diz Clarice Lispector (2008): "até cortar os defeitos pode ser 
perigoso - nunca se sabe qual defeitos sustenta nosso edifício interno."

\section{PRO-VOCAR COMO PARTE DA RELAÇÃO CLÍNICA}

Segundo as noções de Binswanger (2019), o movimento clínico precisa ser uma provocação, algo que chame o outro para a vocação de ser, mas não no sentido de uma essência herdada do sobrenatural como nos é comum conhecer nas religiões cristãs, e sim em um sentido voltado para a etimologia da palavra, ou seja, um chamado. A clínica fenomenológico-existencial caminha, fortalecendo o chamado para a liberdade de ser, porém, com paciência, aguardando o momento da possibilidade de ser. É essa força que se exerce na relação com o outro, a pro-vocação, o chamado.

Sustentar um chamado à liberdade não significa levar o outro a sair do lugar onde ele se encontra, liberdade significa, também, poder ser livre para permanecer no mesmo lugar, escolher ficar, escolher não modificar sua conduta ou seus planos. Liberdade não significa, obrigatoriamente, mudança; em outras palavras, nosso compromisso terapêutico não é com a mudança, mas com a sustentação do aberto (Feijoo, 2017) que possibilita ao outro ser, de maneira pessoal, seu si mesmo.

Não é incomum ouvir que pacientes sem mudança vivem um processo terapêutico ruim, mas questiona-se aqui tais percepções, pois pode ser que a afirmação da liberdade por meio da terapia sustente o desejo de permanecer onde se está.

É preciso entender que sustentar uma clínica para as possibilidades amplas não garante que todos serão transformados, mas, como o compromisso não é com a mudança, o saber-fazer caminha chamando o outro à possibilidade de tornar-se responsável pela maneira como constrói suas articulações de mundo.

Busca-se tornar nítida a liberdade a partir das intervenções provocativas, e a partir daí é dado espaço para que o outro faça o movimento que melhor lhe caiba. Se assim não fosse, estaríamos agindo ainda de maneira identitária. Segundo palavras de Feijoo (2011), devemos dar um passo atrás e deixar com que o outro tutele sua própria existência.

Pro-vocar, sustentar o chamado, significa, cuidar para que o espaço onde 
se dá a análise da existência - a terapia - se constitua a partir de uma relação que não sustente expectativas, mas que apenas deixe acontecer, deixe se dar a condição performática da existência a partir de seu caráter de poder-ser.

Não há moldes, e por isso não há técnicas terapêuticas padronizadas para nós, formulamos clínicas da transgressão, e isso quer dizer que somente o fato de sustentarmos o caráter aberto da existência, sua essência de indeterminação, já rompe as amarras calcificadas da contemporaneidade e de seus ditames formuladores de massas homogeneizadas. Nas palavras de Alexandre Cabral (2018), "todo pensamento ou modo de ser transgressor acaba sendo, portanto, produtor de resistência" (p.25)

Pro-vocar deve nos remeter à atitude de realmente utilizar de acidez na relação com o outro, de provocações que suscitem um refletir, um pensar novamente, um reconsiderar. Palavras, ideias, exemplos, músicas, poemas, são algumas das ferramentas possíveis para provocar, suscitar a recordação do vir-aser, da mudança. A pro-vocação terapêutica aqui vai agir para a liberdade, para o desmonte da padronização, para a singularização; vai agir contrária à ortopedia das existências, vai criar. Como nos diz Pompeia (2000), "a linguagem da terapia é poética"(p.22).

\section{SUSTENTAR O PODER-SER COMO A POSSIBILIDADE MAIOR}

Então o que fazemos? Fazemos nada mais do que pacientemente aguardar o movimento performático da existência que se apresenta diante de nós e que pode - ou não - corresponder à provocação clínica, ao chamado para o poder-ser. Em outras palavras, trabalha-se para sustentar o aberto aguardando 0 momento em que se dará algo (Feijoo, 2017). Que algo? Não se sabe.

Saber o que se dará nos leva novamente ao âmbito da metafísica positivista, para saber o que vem por seguinte seria necessário que a existência fosse já determinada; se quisermos saber qual algo pode surgir estaremos nos rendendo ao chamado da técnica em forçar o desvelamento do fenômeno segundo nossas prescrições.

O clínico fenomenólogo lida com o vazio, ele não sabe - mesmo sabendo - ele rejeita definir - mesmo podendo. Somos estudiosos do caminho do desconhecer, buscamos conhecer para, então, não-saber, só assim poderemos 
nos surpreender a cada vez com o desvelamento de cada fenômeno que se coloca diante de nós.

Um olhar que já sabe não se surpreende, não se solta na relação da descoberta. Nas palavras de Ailton Krenak (2019):

Talvez estejamos tão condicionados a uma ideia de ser humano e a um tipo de existência. Se a gente desestabilizar esse padrão, talvez a nossa mente sofra uma espécie de ruptura, como se caíssemos num abismo. Quem disse que a gente não pode cair? Quem disse que a gente já não caiu? Por que temos tanto medo assim de uma queda se a gente não fez nada nas outras eras senão cair? (p.57).

\section{CONCLUSÃO}

O que se buscou nessa pequena discussão foi propor horizontes para a prática clínica, um espaço onde o ser-com com propósitos de cuidado ôntico possa se dar. Penso que fenomenologicamente é difícil padronizarmos técnicas, pois aí seríamos, mais uma vez, endeusados pelos determinismos, e não podemos deixar de considerar que nem todos respondem da mesma forma às técnicas postas como adequadas ao contexto clínico, cada ação específica assume, dentro de cada intervenção clínica, um aspecto distinto na vida de quem recebe 0 ato proferido, cada intervenção terapêutica exige o conhecer da história na qual se intervém.

O que podemos fazer é possibilitar uma noção tão crítica que nos leve a rever os modelos de mundo vigentes e também as formas de atuações em psicologia a fim de acompanharmos, na medida do possível, o caráter performático existencial que coloca o humano sempre em fluxo, e portanto, em

mutação incessante. Uma prática fiel a esse caráter precisa estar aberta e disponível ao movimento, e para isso a crítica desconstrutiva se faz fundamental.

Encerra-se deixando, como no começo, um poema de Clarice Lispector (2020, p.17) , talvez um texto que expresse o que seria o ato terapêutico para os fenomenólogos: "Mamãe vi um filhote de furacão, mas tão filhotinho ainda, tão pequeno ainda, que só fazia mesmo era rodar bem de leve três folhinhas na esquina..." 
Pro-vocações são furacões filhotinhos, que talvez quando proferidas em palavras, ou em silêncios, ou num olhar, num levantar de sobrancelha, num sorriso... pouco façam aparentemente, mas, que em algum momento, na indeterminação de cada ser sustentada em nossas relações terapêuticas, possam ser avassaladoras em seu processo performático de ser.

Às vezes, o que fazemos é, somente, levantar algumas folhinhas. 


\section{REFERÊNCIAS}

BARIANI, E. O Labirinto de dédalos: a idéia de mundo como horizonte da existência humana. Curitiba: CRV, 2018.

BINSWANGER, L. Psicoterapia e análise existencial: ensaios, conferências e outros documentos. 1. ed. Rio de Janeiro: Via Verita, 2019.

CABRAL, A. Psicologia pós-identitária: da resistência existencial à crítica das matrizes cristãs da psicologia clínica moderna. 1. ed. Rio de Janeiro: Via Verita, 2018.

CABRAL, A. Desidentidades e resistências: ensaio de alterogêneses políticoexistenciais. Rio de Janeiro: Via Verita, 2020.

CASANOVA, M. Mundo e historicidade: leituras fenomenológicas de Ser e Tempo: volume um: existência e mundaneidade. 1. ed. Rio de Janeiro: Via Verita, 2017.

FEIJOO, A. M. L. C. A clínica psicológica: sei que é difícil, mas vou falar mesmo assim. In: FEIJOO, A. M. L. C.; VORSATZ, I.; LESSA, M. B. M. F. L. Poesia e prosa em diálogo com a clínica psicológica. Rio de Janeiro: IFEN, 2021.

FEIJOO, A. M. L. C. A existência para além do sujeito: a crise da subjetividade moderna e suas repercussões para a possibilidade de uma clínica psicológica com fundamentos fenomenológico-existenciais. 1. ed. Rio de Janeiro: Edições IFEN: Via Verita, 2011.

FEIJOO, A. M. L. C. Existência e psicoterapia: da psicologia sem objeto ao saberfazer na clínica psicológica existencial. 1. ed. Rio de Janeiro: IFEN, 2017.

FEIJOO, A. M. L. C. Hybris y psicoterapia como possibilidad de rescate de la medida existencial. In: Fenomenologia e práticas clínicas III. Rio de Janeiro: IFEN, 2020.

FOUCAULT, M. A verdade e as formas jurídicas; tradução de Eduardo Jardim e Roberto Machado. Rio de Janeiro: NAU, 2013.

FOUCAULT, M. História da sexualidade: a vontade de saber. Tradução de MAria Thereza da Costa Albuquerque e J. A. Guilhon Albuquerque. 9 ed. Rio de Janeiro/São Paulo: Paz e Terra, 2019.

HOLANDA, A. F. Fenomenologia e humanismo. Curitiba: Juruá, 2014.

LISPECTOR, C. Para não esquecer. Rio de Janeiro: Rocco, 2020.

LISPECTOR, C. Carta. 2008. Disponível em: https://claricelispector.blogspot.com/2008/02/carta.html .

PESSOA, F. Livro do desassossego. Jandira,SP: Ciranda Cultural, 2019. 
POMPEIA, J. A; SAPIENZA, B. T. Os dois nascimentos do homem. Rio de Janeiro: Via Verita, 2011.

POMPEIA, J. A. Desfecho: encerramento de um processo. In: Associação Brasileira de Daseinsanalyse. n.9. (p. 31-43) São Paulo: A Associação, 2000.

SÁ, R. N. Para além da técnica: ensaios fenomenológicos sobre psicoterapia, atenção e cuidado. 1. ed. Rio de Janeiro: Via Verita, 2017.

KRENAK, A. Ideias para adiar o fim do mundo. 1. ed. São Paulo: Companhia das Letras, 2019.

ZANETTI, F. A clínica fenomenológico-existencial: um fazer terapêutico em direção a liberdade constitutiva. Hígia Ciência. n. 6. v.1. 2020. Disponível em: https://9cd76b29-5cb6-4d5c-8de7-

2bfe4fce1436.filesusr.com/ugd/7979f4_027b74f0ada44ef9ad7cf2c6280d37a7.pd $f$ 